\title{
A ring monopole quad band antenna loaded with metamaterial and slots for wireless applications
}

\author{
Basavalinga Swamy', C. M Tavade², Kishan Singh ${ }^{3}$ \\ ${ }^{1}$ Department of Electronics \& Communication Engineering, Lingaraj Appa Engineering College, Bidar, Karnataka, India \\ ${ }^{2}$ Department of Electronics \& Communication, Basavakalyan Engineering College, Karnataka, India \\ ${ }^{3}$ Department of Electronics \& Communication, Guru Nanak Dev Engineering College, Bidar, Karnataka, India
}

\begin{tabular}{l} 
Article Info \\
\hline Article history: \\
Received May 22, 2021 \\
Revised Jun 1, 2021 \\
Accepted Aug 19, 2021 \\
\hline
\end{tabular}

\section{Keywords:}

Metamaterial

Multiband

RSRR

S-parameters

Waveguide medium

\begin{abstract}
The present wireless applications demand a compact, multi-operated, and stable radiation pattern antenna with good gain and impedance matching performance. To accomplish this requirement. In this paper, we propose a compact metamaterial structure loaded quad band antenna. The structural specifications/layout of the antenna consists of a circular ring monopole fed by a microstrip line. The ground part of the antenna is loaded with a metamaterial rectangular split-ring resonator (RSRR), an L-shaped slot, and two horizontally placed rectangular slots parallel to each other. No external matching circuit is utilized and impedance matching is solely controlled by the placement of slots. The antenna shows operation at $2.1 \mathrm{GHz}(2.01-2.24$ $\mathrm{GHz}$, a bandwidth of $230 \mathrm{MHz}$ (WLAN)), $4.5 \mathrm{GHz}(4.35-4.66 \mathrm{GHz}$, a bandwidth of $310 \mathrm{MHz}$ (C-band)), $5.5 \mathrm{GHz}$ (5.37-5.77 GHz bandwidth of 400 $\mathrm{MHz}$ (WiMAX)), and 7.2 GHz (7.08-7.33 GHz, a bandwidth of $250 \mathrm{MHz}$ (satellite band)). The antenna exhibits good gain and stable radiation pattern in both the plane and thus can be utilized for aforementioned applications.
\end{abstract}

This is an open access article under the $\underline{C C B Y-S A}$ license.

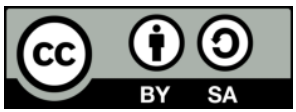

\section{Corresponding Author:}

Basavalinga Swamy

Department of Electronics \& Communication Engineering

Lingaraj Appa Engineering College

Bidar, Karnataka, India

Email: basavalingaswamy2020@gmail.com

\section{INTRODUCTION}

The recent development in modern wireless communication systems stresses challenging antenna features. The microstrip patch antennas (MPA's) are increasingly fetching a wide range of applications in wireless communication as these antennas can be easily printed onto a circuit board. The MPAs are fascinating due to their compact conformal low profile configuration, easier to assimilate with monolithic microwave integrated circuits (MMICs), multiband operations, helps in achieving linear and circular polarization, and ease in voluminous production as it uses printed circuit technology, and so on. As the wireless devices now are more enthusiastic towards integrating multiple services from a single antenna, thus the development of multiband has become a prime area of research. More specifically the compact antenna with multiband nature has become the current demand of all the wireless devices [1]-[5].

In regard to this literature reports various method to achieve multiband in an antenna like utilization of slots and slits in the radiating or ground part [6]-[9], parasitic elements [10], [11], fractals [12]-[19], stubs [20], [21] various feeding techniques [22]-[24]. Recently, the usage of metamaterial to incorporate multiband phenomenon in antenna design has gained the significant attention. The striking properties of metamaterials such as negative permeability, permittivity and refractive index helps in accomplishing the narrowband operation at the required frequency. The first concept of metamaterial was proposed by Veselgo in 1968 [25]. 
Till date various metamaterial structures have been proposed like split ring resonator [26], square complimentary split ring resonator [27], circular split ring resonator [28], gapless circular split ring resonator [29] to accomplish multiband operation in the antenna.

In this study, a compact rectangular split-ring resonator (RSRR) loaded antenna is designed. The antenna has a circular ring-like monopole structure and is loaded with slots and metamaterial structure RSRR. The loading of these structures in the antenna results in operation at four bands i.e., 2.1, 4.2, 5.5, and 7.2 GHz. Detailed parametric analysis is carried out to fix the dimension of the antenna. The antenna performances are studied with the help of S-parameters, current distribution, VSWR, impedance behaviour, and $3 \mathrm{D}$ gain pattern. The main advantage of the antenna is its compact dimension and quad band operations with good gain and radiation performance. All the analysis of the antenna is performed in HFSS.

\section{DESIGN METHODOLOGY AND CONFIGURATION}

The objective of the proposed study is to design a metamaterial-loaded dual-band antenna. To incorporate this the said antenna is designed into six steps and this design is demonstrated in Figure 1. Initially, a circular patch is chosen with a full ground part. The main idea behind choosing the circular radiating part is to accomplish uniform backflow of current from edges to center. However in the case of step 1 termed as "Ant-1", there is no operating band obtained (as no portion of the graph is below $\mathrm{S}_{11}<-10 \mathrm{~dB}$ ) as depicted in Figure 2. To accomplish the operating band, the circular shape radiating part is transformed into a circular ring-like structure to disturb the radiator current flow. Also, the ground part is etched to three fourth and termed as "Ant-2" as demonstrated in Figure 1. By utilizing this configuration one can see that due to the circular ring radiator two wideband operating bands are achieved around $5.8 \mathrm{GHz}$ and $7.3 \mathrm{GHz}$. The wideband nature of this band is due to the etching of the ground plane. However, to get a narrow multiband operation, the ground plane of "Ant-2" is again modified by introducing an L-shaped slot, while retaining the circular ring radiator structure. The obtained structure is termed as "Ant-3" as depicted in Figure1 and its corresponding S11response is outlined in Figure 2. From the $S_{11}$ response curve, one can notice that due to the addition of an L-shaped slot, the antenna now shows triple-band operation, wherein the fundamental operating mode is obtained around $4.6 \mathrm{GHz}$, while the other two wideband operating bands are obtained around $6 \mathrm{GHz}$ and $7.4 \mathrm{GHz}$. However, the demerit of this configuration is that there is a poor impedance matching observed around 6.5 to $7 \mathrm{GHz}$. To solve this design problem a horizontal rectangular slot is placed beside the L-shaped slot in the ground part of "Ant-3". The addition of this part gives rise to a new configuration and is termed as "Ant-4". The addition of a rectangular slot solves the problem of impedance matching of "Ant-3". But demerit now is that the obtain configuration (i.e., "Ant-4") operates at only two bands (i.e., at $4.2 \mathrm{GHz}$ and $5.4 \mathrm{GHz}$ ) as shown in Figure 2. To achieve triple-band from this configuration, "Ant-4" is further modified by placing one more slot parallel to the above introduced rectangular slot and this configuration is termed as "Ant-5". It can be noticed from Figure 2, that this antenna shows three bands of operation with good impedance matching. These bands are obtained at $4.2 \mathrm{GHz}$ (C-band), 5.1GHz (WLAN), and $7.4 \mathrm{GHz}$ (satellite band).

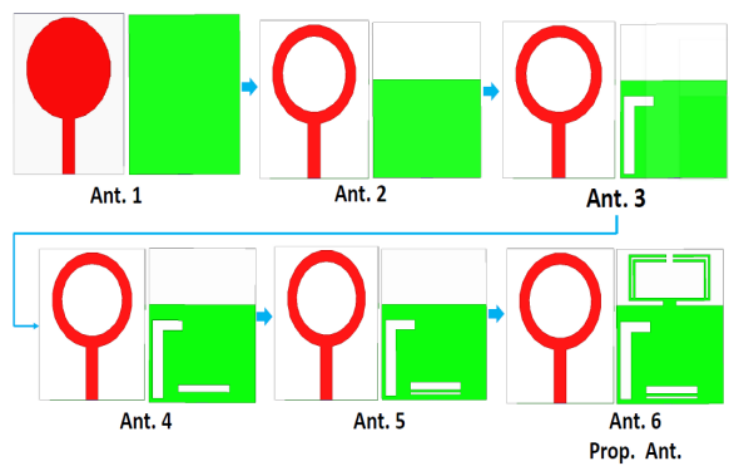

Figure 1. Evolution of proposed antenna

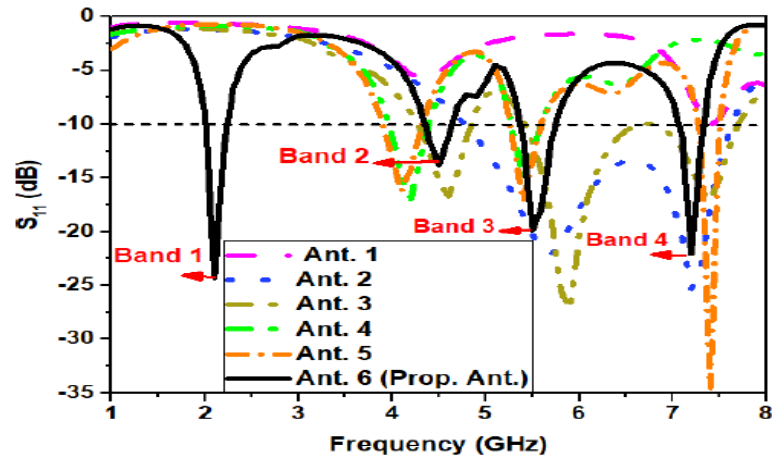

Figure 2. S-parameter of the evolution of the antenna

To make the antenna more versatile and operates at one more band (quad band) a metamaterial structure is loaded at the ground plane. This metamaterial structure is nothing but a rectangular split-ring resonator (RSRR) and is supported on a small rectangular stub. This structure is now called "Ant-6" and also the proposed antenna as shown in Figure 1. The loading of this metamaterial structure results in a solenoidal 
current which induces fluctuations in the magnetic field thereby resulting in narrowband operation (magnetic response) at $2.1 \mathrm{GHz}$ (WLAN) as shown in Figure 2. It is to be noticed here that the radiator shape is still unchanged and it remains to be a circular ring. The detailed analysis of metamaterial structure is RSRR is further discussed in section 4. Thus the proposed antenna now finally operates at quad band (i.e., 2.1, 4.5, 5.5, and 7.2 GHz) with better impedance matching at all the bands.

The proposed antenna nomenclature is demonstrated in Figure 3. It can be studied that the antenna consists of a circular ring-like radiator which is fed by a microstrip line to achieve an impedance matching of $50 \Omega$. The ground plane consists of Land rectangular slots with a metamaterial loading. The detailed dimension layout of the said antenna is further illustrated in Figure 4. The inner and outer radius of the rings are represented as $R_{1}$ and $R_{2}$. The overall size of the substrate is given as $\left(L_{s} \times W_{s}\right)$. The metamaterial structure has an overall dimension of $\left(M_{5} \times M_{1}\right)$ with a split gap of $M_{3}$. The L-shaped slot has a dimension of $\left(L_{1} \times L_{2} \times L_{3}\right)$, the upper rectangular slot at the ground plane has a dimension of $\left(S_{2} \times S_{1}\right)$ while the below rectangular slot is placed parallelly to the upper rectangular slot has a dimension of $\left(S_{4} \times S_{2}\right)$. The dimension of the overall antenna is outlined in Table 1.

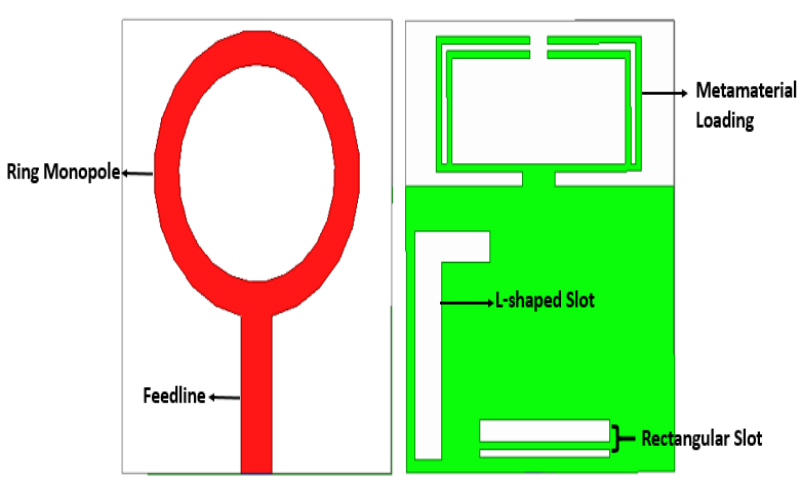

Figure 3. Nomenclature of the proposed antenna

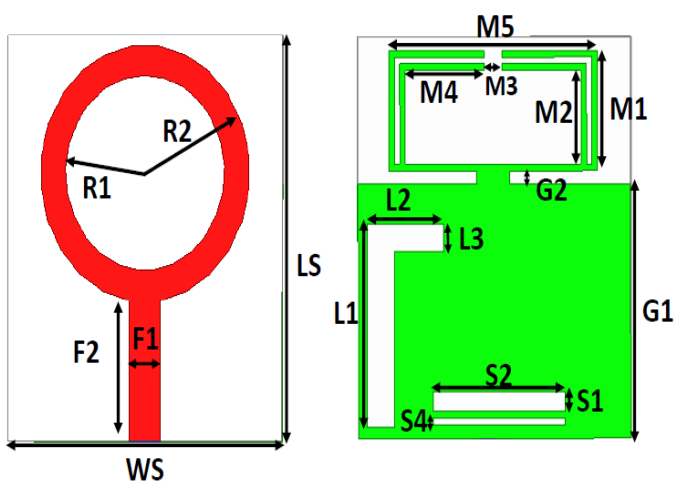

Figure 4. Geometrical dimensions of the proposed antenna

Table 1. Dimension (millimeter) of antenna

\begin{tabular}{ccc}
\hline value $(\mathrm{mm})$ & value $(\mathrm{mm})$ & value $(\mathrm{mm})$ \\
\hline$W_{s}=24.8$ & $M_{5}=19$ & $L_{2}=7, L_{3}=2$ \\
$L_{s}=30$ & $M_{1}=9$ & $S_{1}=1.5$ \\
$F_{1}=2.8$ & $M_{2}=7.5$ & $S_{2}=12$ \\
$F_{2}=10.4$ & $M_{4}=7.7$ & $S_{4}=0.5$ \\
$R_{1}=6.7$ & $M_{3}=1.6$ & $G_{1}=19$ \\
$R_{2}=9.5$ & $L_{1}=15.2$ & $G_{2}=1$ \\
\hline
\end{tabular}

\section{ANALYSIS OF THE METAMATERIAL STRUCTURE RSRR}

The main purpose of using RSRR is to accomplish a narrowband operation around $2.1 \mathrm{GHz}$ (WLAN), without physically increasing the overall size of the antenna. As it can be noticed that, this RSRR is just supported on a rectangular stub on the ground part of the antenna, thus retaining the compact size of the antenna. To study the metamaterial properties behavior of the proposed RSRR its analysis is carried out in waveguide medium [30] as demonstrated in Figure 5. The RSRR is placed inside a waveguide environment where it is subjected to boundary conditions (i.e., perfect electric conductor at top plane and perfect magnetic conductor at front plane). To study the reflected signal behavior (S-parameters), the power is applied at port 1 and the corresponding output behavior is observed at port 2. The obtained passband characteristic of this RSRR is depicted in Figure 6. It is observed that the transmission coefficient (S21) at $1.6 \mathrm{GHz}$ is below $-10 \mathrm{~dB}$ whereas the $\mathrm{S} 11$ is around $0 \mathrm{~dB}$. This exhibits the passband behavior of the proposed RSRR at $1.6 \mathrm{GHz}$ when it is utilized as a radiator at the ground part of the antenna. It is worthy to note here that due to integration of RSRR with antenna this band get shifted to $2.1 \mathrm{GHz}$, which is mainly due to the increases the total current length path of the antenna, thereby changing the wavelength. 


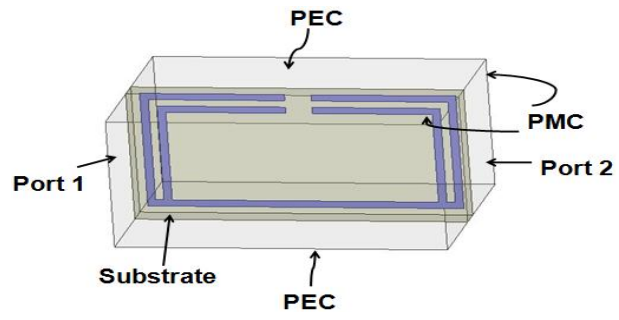

Figure 5. RSRR analysis in waveguide medium

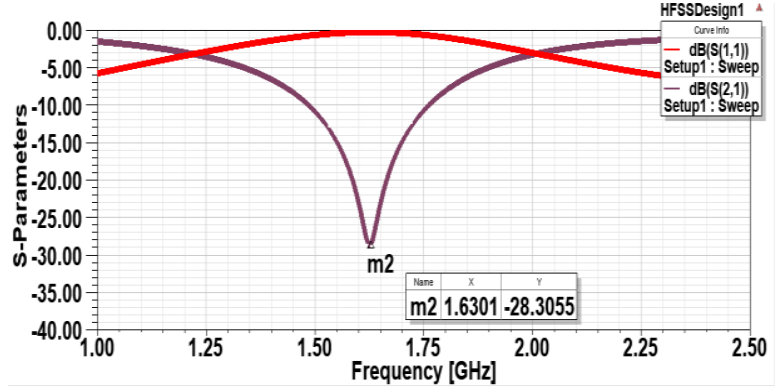

Figure 6. S-parameters of the RSRR

\section{PARAMETRIC STUDY OF THE ANTENNA}

To accomplish the optimum dimension of the antenna its parametric investigations are carried out and are described in Figures 7 to Figure 10.

\subsection{Effect of $\mathbf{R}_{2}$}

To observe the effect of R2on the operating performance of the antenna, its study is demonstrated in Figure 7 by varying R2 from $9.45 \mathrm{~mm}$ to $9.55 \mathrm{~mm}$. At $9.45 \mathrm{~mm}$ only triple-band operations are observed while the $\mathrm{S} 11$ value of the fundamental band is around $-5 \mathrm{~dB}$. At $\mathrm{R} 2=9.55 \mathrm{~mm}$ quad band operation is observed, however the impedance matching of the first resonance is poor. At fixed dimension $\mathrm{R} 2=9.55 \mathrm{~mm}$ all four quad band are obtained with better impedance matching.

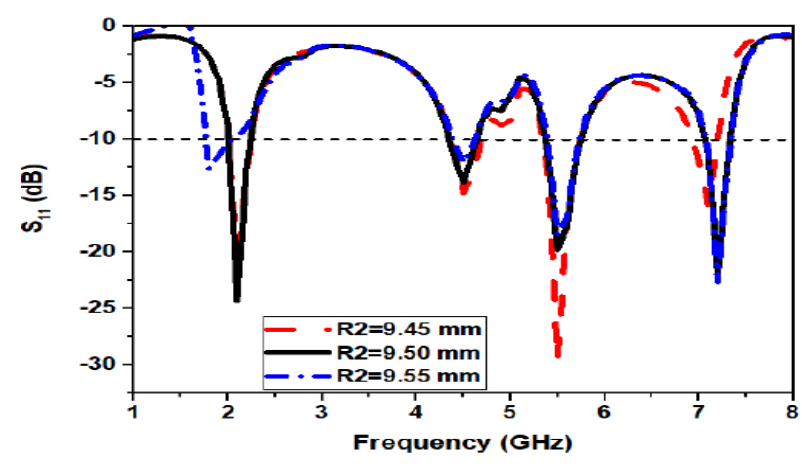

Figure 7. Parametric analysis by varying R2

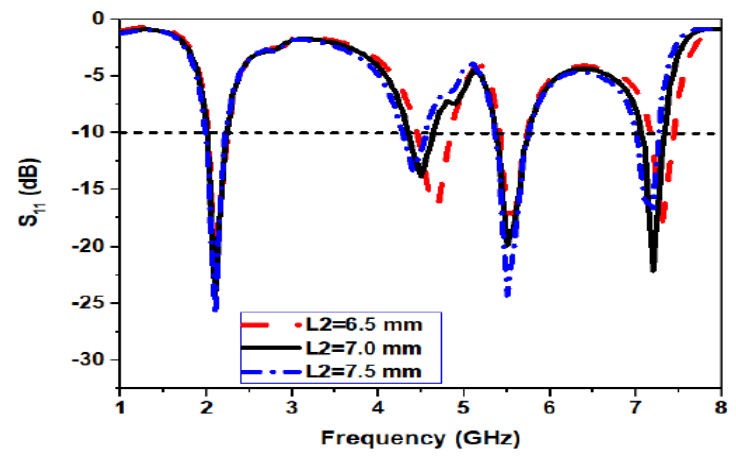

Figure 8. Parametric analysis by varying L2

\subsection{Effect of $L_{2}$}

To study the L2 on the performance antenna, its dimension is varied from $6.5 \mathrm{~mm}$ to $7.5 \mathrm{~mm}$ and is demonstrated in Figure 8. At L2 $=6.5 \mathrm{~mm}$ all four bands are obtained however the $\mathrm{S} 11$ value at each operating band is relatively less. At L2 $=7.5 \mathrm{~mm}$ also all four bands are obtained however poor impedance matching is observed at the second resonance. At optimized dimension L2=7 $\mathrm{mm}$ all four bands are obtained with better $\mathrm{S} 11<-10 \mathrm{~dB}$ value.

\subsection{Effect of $S_{2}$}

To observe the effect of S2 its parametric investigation is performed by varying S2 from $11.5 \mathrm{~mm}$ to $12.5 \mathrm{~mm}$ as depicted in Figure 9. At S2=11.5 mm only dual operation is achieved since the S11 value at first and second resonance is above $-10 \mathrm{~dB}$. At $\mathrm{S} 2=12.5 \mathrm{~mm}$ all four bands are obtained but with poor impedance matching at the second band. At the fixed dimension. At S2=12 mm quad band operation is achieved with better impedance matching.

\subsection{Effect of $S_{4}$}

Similar to the parametric study above, $\mathrm{S} 4$ parametric analysis is carried out by varying it from $0 \mathrm{~mm}$ (no slot) to $1.5 \mathrm{~mm}$. when the lower slot width is kept $0 \mathrm{~mm}$ (no slot) and $1.5 \mathrm{~mm}$ then we can observe from Figure 10 that there is a very poor impedance matching at second and fourth resonance. At $\mathrm{S} 4=0.5 \mathrm{~mm}$ all four bands with better impedance matching are obtained. 


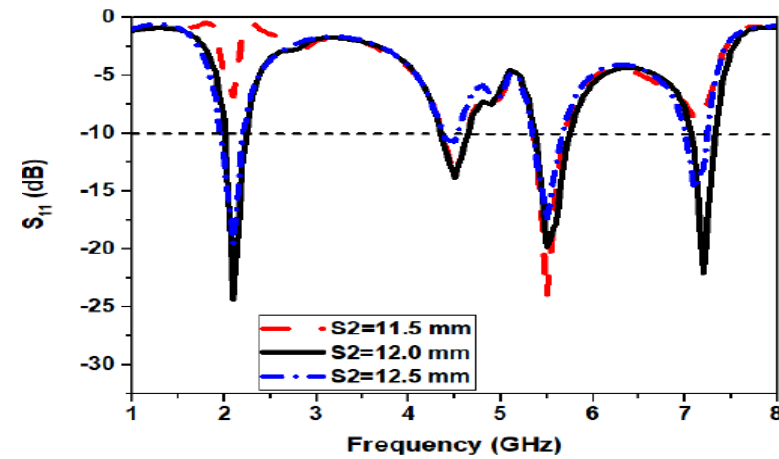

Figure 9. Parametric analysis by varying S2

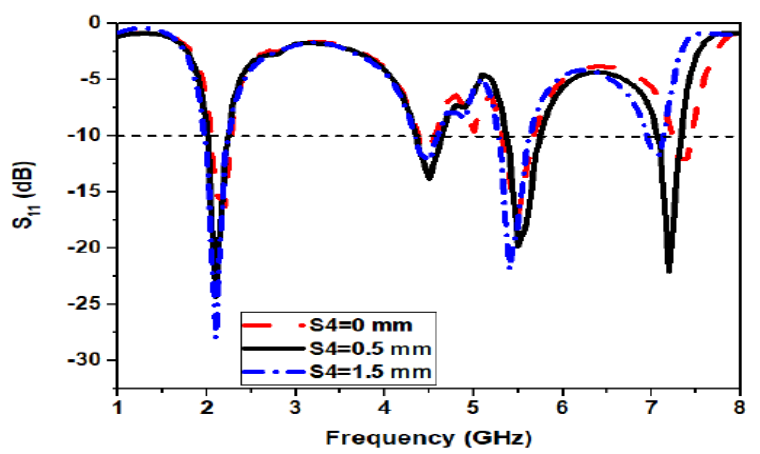

Figure 10. Parametric analysis by varying S4

\section{RESULTS AND DISCUSSIONS}

The Proposed design in Figure 4 is simulated in HFSS, using lumped port excitation in FR4 substrate with dielectric constant 4.4 and thickness $1.6 \mathrm{~mm}$ and loss tangent of 0.02 . The prototype of the fabricated antenna is illustrated in Figure 11. The final S11 obtained after the simulation and measurement is depicted in Figure 12. The antenna shows the first resonance operation from 2.01 to $2.24 \mathrm{GHz}$, with a center frequency of $2.1 \mathrm{GHz}$ (WLAN) in simulation and from 2.1 to $2.3 \mathrm{GHz}$, with a center frequency of $2.2 \mathrm{GHz}$ in measurement. The second band operation ranges from 4.35 to $4.66 \mathrm{GHz}$, with a center frequency of $4.5 \mathrm{GHz}$ (C-band) in simulation and from 4.3 to $4.7 \mathrm{GHz}$, with a center frequency of $4.6 \mathrm{GHz}$ in measurement. The third band operation is observed from 5.37 to $5.77 \mathrm{GHz}$, with a center frequency of $5.5 \mathrm{GHz}$ (WiMAX)) in simulation and from 5.4 to $5.8 \mathrm{GHz}$, with a center frequency of $5.6 \mathrm{GHz}$ in measurement. The fourth band operation ranges from 7.08 to $7.33 \mathrm{GHz}$, with a center frequency of $7.2 \mathrm{GHz}$ (Satellite band) in simulation and from 7.2 to $7.5 \mathrm{GHz}$, with a center frequency of $7.3 \mathrm{GHz}$ in measurement.

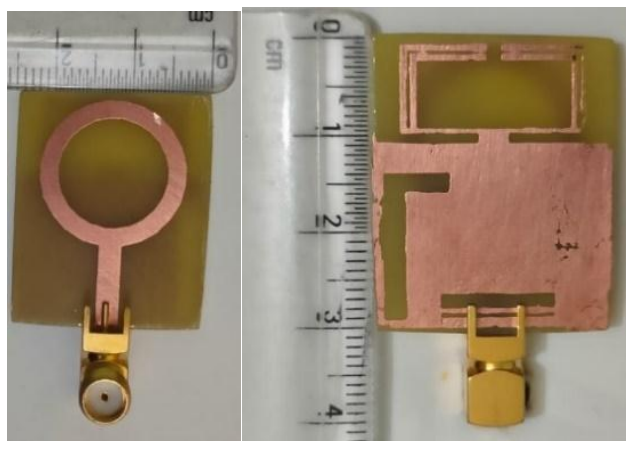

Figure 11. Prototype of the proposed antenna

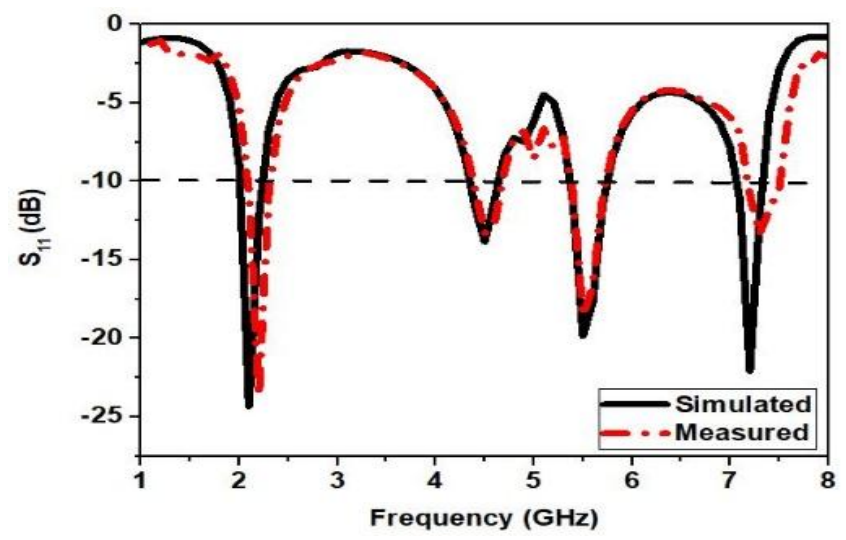

Figure 12. Simulated and measured S11 of the proposed antenna

The surface current pattern of the proposed RSRR loaded antenna is depicted in Figure 13. At 2.1 $\mathrm{GHz}$ high current density is seen around the RSRR, thereby proving that this operation is due to metamaterial structure. At $4.5 \mathrm{GHz}$ the lower-left portion of the circular ring radiator and the L-shaped slot shows a good current pattern. At $5.5 \mathrm{GHz}$, a dense current is observed around the right position of the circular ring radiator and the center back part of the ground plane. At 7.2 GHz the impedance matching is improved by a lower rectangular slot, thus a dense current is observed in a parallel path between horizontal rectangular slots.

The impedance plot of the proposed antenna is depicted in Figure 14. At $2.1 \mathrm{GHz}$, the antenna shows an impedance of (52.6 - j5.68) $\Omega$. At $4.5 \mathrm{GHz}$, it exhibits an impedance of (73.3 - j9.3) $\Omega$. Similarly, at 5.5 and $7.2 \mathrm{GHz}$ it depicts an impedance of (54.9 - j 9.5) and (44.2 - j 4.6) respectively. Thus it can observe that impedances are closed to $50 \Omega$ except at $4.1 \mathrm{GHz}$ which may be due to the utilization of slotted structure at the ground part. 


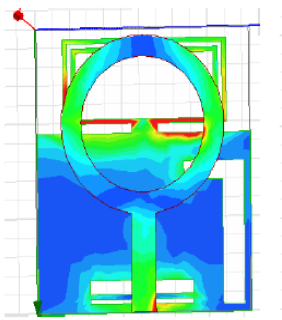

(a)

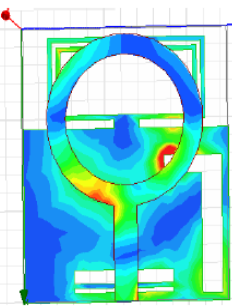

(b)

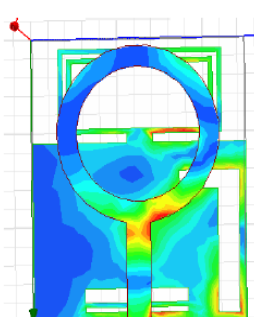

(c)

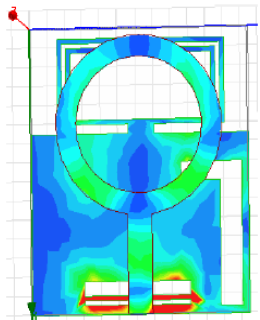

(d)

Figure 13. Surface current distribution of the proposed antenna at (a) $2.1 \mathrm{GHz}$, (b) 4.5 , (c) 5.5 and $7.2 \mathrm{GHz}$

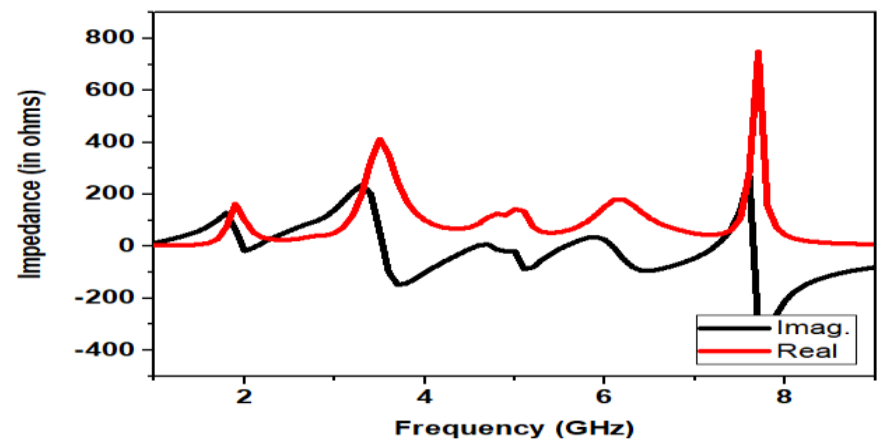

Figure 14. Z-parameter of the proposed antenna

The 3D gain radiation pattern of the RSRR antenna is illustrated in Figure 15. At $2.1 \mathrm{GHz}$, a bidirectional pattern with a gain of $0.55 \mathrm{~dB}$ is observed. At $4.1 \mathrm{GHz}$ an omnidirectional pattern with a gain of around $0.69 \mathrm{~dB}$ is obtained. At 5.5 and $7.2 \mathrm{GHz}$, the radiation is bidirectional and shows a gain of around 2.6 and $2.2 \mathrm{~dB}$ respectively. Thus the obtained gain is good enough to be utilized for the aforementioned wireless communication.

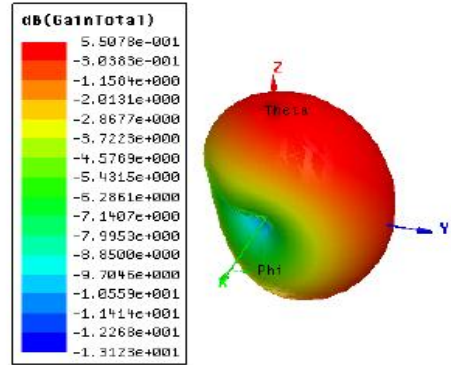

(a)

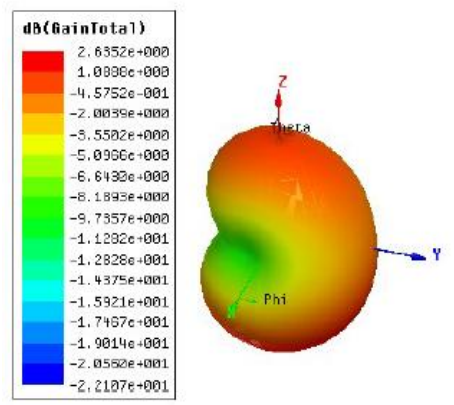

(c)

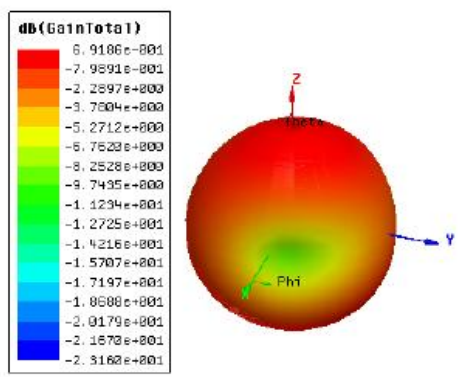

(b)

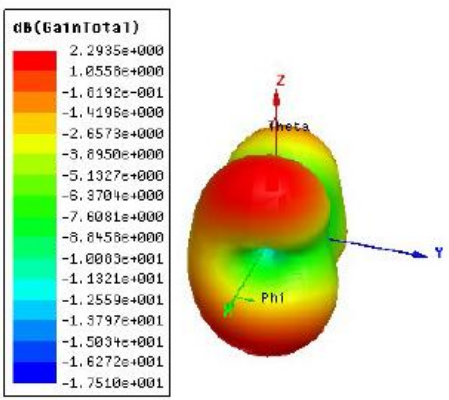

(d)

Figure 15. 3D gain pattern of the proposed antenna at, (a) $2.1 \mathrm{GHz}$, (b) 4.5 , (c) 5.5 , (d) $7.2 \mathrm{GHz}$ 


\section{CONCLUSION}

The design of a metamaterial structure RSRR loaded antenna with slots is accomplished. The antenna shows an operation at 2.1 (WLAN), 4.5 (C-band), 5.5 (WiMAX), and $7.2 \mathrm{GHz}$ (satellite band) with better impedance matching at all the bands. To fix the dimension of a particular parameter of the antenna, parametric investigations are carried out. This investigation shows that even the incremental variation in the dimensions of the antenna its performance is affected to large extent in terms of the number of operating band and impedance matching. The designed antenna is compact and exhibits good gain and stable radiation at all the operating frequencies and thus can be considered a very suitable candidate for the aforementioned wireless applications.

\section{ACKNOWLEDGEMENT}

We are very much thankful to VGST for sanctioning of HFSS Software for Simulation to R\&D Centre, Electronics and Communication Department GNDEC Bidar.

\section{REFERENCES}

[1] T. Ali, B. K. Subhash, and R. C. Biradar, "A miniaturized decagonal Sierpinski UWB fractal antenna," Progress In Electromagnetics Research, vol. 84, pp. 161-174, 2018, doi: 10.2528/PIERC18040605.

[2] S. A. W. Mohammad, M. M. Khaleeq, T. Ali and R. C. Biradar, "A miniaturized truncated ground plane concentric ring shaped UWB antenna for wireless applications," 2nd IEEE International Conference on Recent Trends in Electronics, Information \& Communication Technology RTEICT, 2017, pp. 116-120, doi: 10.1109/RTEICT.2017.8256569.

[3] I. Khan, T. Ali, G. D. Devanagavi, S. KR, and R. C. Biradar, "A Multiband Slot Antenna loaded with Stubs for WLAN/WiMAX/Satellite TV Applications," Advanced Electromagnetics, vol. 7, no. 5, pp. 74-81, 2018, doi: 10.7716/aem.v7i5.791.

[4] P. M. Paul, K. Kandasamy, and M. S. Sharawi, "A corner expanded slot antenna loaded with copper strips for dual- band circular polarization characteristics," Microwave and Optical Technology Letters, vol. 62, no. 1, pp. 491-497, 2019, doi: 10.1002/mop.32044.

[5] R. Hussain, M. U. Khan, E. Almajali, and M. S. Sharawi, "Split-ring-resonator-loaded multiband frequency agile slot-based MIMO antenna system," IET Microwaves, Antennas \& Propagation, vol. 13, no. 14, pp. 2449-2456, 2019, doi: 10.1049/iet-map.2019.0333.

[6] T. Khan, and M. Rahman, "Design of low-profile frequency reconfigurable antenna for multiband applications," International Journal of Electronics Letters, pp, 1-22, 2020, doi: 10.1080/21681724.2020.1818836.

[7] A. Kunwar, A. K. Gautam, and K. Rambabu, "Design of a compact U-shaped slot triple band antenna for WLAN/WiMAX applications," AEU-International Journal of Electronics and Communications, vol. 71, pp. 82-88, 2017, doi: 10.1016/j.aeue.2016.10.013.

[8] P. S. Bakariya, S. Dwari, M. Sarkar and M. K. Mandal, "Proximity-Coupled Microstrip Antenna for Bluetooth, WiMAX, and WLAN Applications," IEEE Antennas and Wireless Propagation Letters, vol. 14, pp. 755-758, 2015, doi: 10.1109/LAWP.2014.2379611.

[9] H. Chen, H. Yang and C. Sim, "Single Open-Slot Antenna for LTE/WWAN Smartphone Application," IEEE Transactions on Antennas and Propagation, vol. 65, no. 8, pp. 4278-4282, Aug. 2017, doi: 10.1109/TAP.2017.2710228.

[10] S. Nallapaneni, and P. Muthusamy, "Design of multiband fractal antenna loaded with parasitic elements for gain enhancement," International Journal of RF and Microwave Computer-Aided Engineering, vol. 31, no. 6, 2021, doi: $10.1002 /$ mmce. 22622 .

[11] S. J. Lee, W. S. Yoon, and S. M. Han, "Planar beam steerable parasitic array antenna system design based on the Yagi-Uda design method," International Journal of Antennas and Propagation, vol. 2019, Article ID 8023712, 2019, doi: 10.1155/2019/8023712.

[12] M. Sakucci, N. Anselmi, S. Gaudos and A. Massa, "Fast design of multiband fractal antennas through a system-bydesign approach for NB-IoT applications," EURASIP Journal on Wireless Communications and Networking, vol. 2019, no. 68, pp. 1-15, 2019, doi: 10.1186/s13638-019-1386-4.

[13] N. Fathima, K. S. Nayana, T. Ali and R. C. Biradar, "A miniaturized slotted ground fractal Koch multiband antenna for wireless applications," 2nd IEEE International Conference on Recent Trends in Electronics, Information \& Communication Technology RTEICT, 2017, pp. 251-255, doi: 10.1109/RTEICT.2017.8256596.

[14] T. Ali, N. Fatima, and R. C. Bidar, "A miniaturized multiband reconfigurable fractal slot antenna for GPS/GNSS/Bluetooth/WiMAX/X-band applications," AEU-International Journal of Electronics and Communications, vol. 94, pp. 234-243, 2018, doi: 10.1016/j.aeue.2018.07.017.

[15] C. Elavarasi and T. Shanmuganantham, "Study and Design of SRR loaded ACS-Fed Multiband Koch star and MinkowskiCurve Fractal-Patch Antenna," TEQIP III Sponsored International Conference on Microwave Integrated Circuits, Photonics and Wireless Networks (IMICPW), 2019, pp. 186-190, doi: 10.1109/IMICPW.2019.8933237.

[16] S. Bukkawar and V. Ahmed, "Square Shaped Fractal Antenna for Multiband Applications," International Conference on Smart City and Emerging Technology (ICSCET), 2018, pp. 1-4, doi: 10.1109/ICSCET.2018.8537305. 
[17] R. Tiwari, "A Multiband Fractal Antenna for Major Wireless communication bands," IEEE International Conference on Electrical, Computer and Communication Technologies (ICECCT), 2019, pp. 1-6, doi: 10.1109/ICECCT.2019.8869139.

[18] S. Subramanian and B. Sundarambal, "Compact Micro Strip Fed Koch Fractal Monopole Loop Antenna For Multiband Performance," 6th International Conference on Advanced Computing and Communication Systems (ICACCS), 2020, pp. 1438-1439, doi: 10.1109/ICACCS48705.2020.9074354.

[19] J. Anguera et al., "Fractal antennas: An historical perspective," Fractal and Fractional, vol. 4, no. 1, pp. 1-26, 2020, doi: $10.3390 /$ fractalfract 4010003 .

[20] N. Sharma, M. Yadav and A. Kumar, "Design of quad-band microstrip-fed stubs-loaded frequency reconfigurable antenna for multiband operation," 4th International Conference on Signal Processing and Integrated Networks (SPIN), 2017, pp. 275-279, doi: 10.1109/SPIN.2017.8049959.

[21] Z. Khan, R. P. Dwivedi and K. Usha Kiran, "Stub loaded compact hexagonal ring antenna for WLAN/WiMAX/ITU applications," TQIP III Sponsored International Conference on Microwave Integrated Circuits, Photonics and Wireless Networks (IMICPW), 2019, pp. 98-102, doi: 10.1109/IMICPW.2019.8933230.

[22] Bugaj, M., R. Przesmycki, L. Nowoseilski, and K. Piwowarczyk, "Analysis different methods of microstrip antennas feeding for their electrical parameters," Proccedings Progress in Electromagnetics Research Letters PIER, 2012, pp. 62-66, Kuala Lumpur, Malaysia.

[23] M. P. Civerelo, "Aperture Coupled Microstrip Antenna Design and Analysis," California Polytechnic State University California state University, Los Angles, 2010.

[24] C. A. Balanis, "Advanced Engineering Electromagnetics," Hoboken, NJ: J. Wiley \& Sons; 2012.

[25] V. G. Vaselago, "The Electrodynamics of Substances with Simultaneously Negative Values of Img Align= Absmiddle Alt $=\epsilon$ Eps/Img and $\mu, "$ Physics-Uspekhi, vol. 10, no. 4, pp. 509-514, 1968, doi: 10.1070/PU1968v010n04ABEH003699.

[26] T. Ali, S. A. W. Mohammad and R. C. Biradar, "A novel metamaterial rectangular CSRR with pass band characteristics at 2.95 and $5.23 \mathrm{GHz}, "$ 2nd IEEE International Conference on Recent Trends in Electronics, Information \& Communication Technology RTEICT, 2017, pp. 256-260, doi: 10.1109/RTEICT.2017.8256597.

[27] R. M. David, M. S. Aw, T. Ali, and P. Kumar, "A Multiband Antenna Stacked with Novel Metamaterial SCSRR and CSSRR for WiMAX/WLAN Applications," Micromachines, vol. 12, no. 2, pp. 1-14, 2021, doi: 10.3390/mi12020113.

[28] W. Ali, E. Hamad, M. Bassiuny, and M. Hamdallah, "Complementary split ring resonator based triple band microstrip antenna for WLAN/WiMAX applications,” Radioengineering, vol. 26, no. 1, pp. 78-84, 2017, doi: 10.13164/re.2017.0078

[29] T. Ali, M. M. Khaleeq, S. Pathan, and R. C. Biradar, "A multiband antenna loaded with metamaterial and slots for GPS/WLAN/WiMAX applications," Microwave and Optical Technology Letters, vol. 60, no. 1, pp. 79-85, 2017, doi: $10.1002 / \mathrm{mop} .30921$.

[30] D. R. Smith, D. C. Vier, T. Koschny, and C. M. Soukoulis, "Electromagnetic parameter retrieval from inhomogeneous metamaterials," Physical review E, vol. 71, no. 3, pp. 1-11, 2005.

\section{BIOGRAPHIES OF AUTHORS}

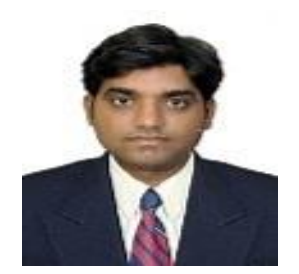

Basavalinga Swamy completed M.Tech. in the stream of ECE. (VLSI Design Embedded system.) in the year 2011 from VTU extension Centre, UTL Technologies LTD Bangalore. He is working as Asst professor in Lingaraj Appa Engineering College, Bidar Karnataka India. He is the Life member of IETE and ISTE He is published several papers in Microstrip Antennas. His area of interests is Antenna and Propagation, VLSI Design and Embedded System. EM fields and Microwave Engineering.

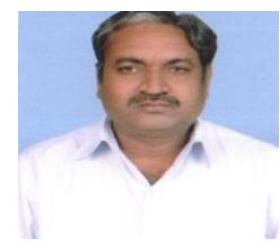

Dr. Chandrashekhar. M.Tavade completed Ph.D in the stream Material Science in the year of 2014 from Gulbarag University, Gulbarga, and Karnataka, India. He is working as Principal Professor in Basavakalyan Engineering College, Basavakalyan Karnataka India. He has more than 36 years Teaching \& Research Experience. He is the Life member of IETE ISTE, MIE, ISOI, IACSIT. He is published several papers in Microstrip Antennas. Electronics and Communication His area of interests is Field Theory, Network Analysis, Signals and Systems.

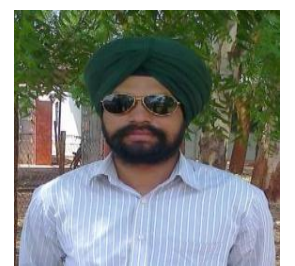

Dr. Kishan Singh completed Ph.D in the stream Microstrip Antennas in the year of 2012 from Gulbarag University, Gulbarga, and Karnataka, India. He is working as Professor in Gurunanak Dev Engineering College, Bidar Karnataka India. He had been awarded as Young Scientist From VGST, Govt of Karnataka. He has more than 15 years Teaching \& Research Experience. He is published several papers in Microstrip Antennas. His area of interests is Antenna and propagation, EM fields and Microwave Engineering. 